\title{
The design of digitized remote system for monitoring sandstone manufacturing throughput
}

\author{
Jing Qian ${ }^{1, a}$, Fenglan $\mathrm{Ma}^{2, \mathrm{~b}}$ \\ 1No16 Gangdubeijie, Zhengzhou, Zhengzhou Municipal Engineering Administration Department, \\ China \\ 2 No67 Huaihelu, Zhengzhou, Zhengzhou Safety Education Center , China \\ aqj6966@126.com,b1749285750@qq.com
}

Keyword: Weight sensor, GPRS, CPU

Abstract. This paper describes the application of a digitized remote sandstone monitoring system on the throughput of coal production, and depicts in detail its main circuitry as well as key components inside the monitoring system

Please keep a second copy of your manuscript in your office. When receiving the paper, we assume that the corresponding authors grant us the copyright to use the paper for the book or journal in question. Should authors use tables or figures from other Publications, they must ask the corresponding publishers to grant them the right to publish this material in their paper.

\section{Introduction}

Background

Current overall production throughput control of mid and small size coal mines are very chaotic. Administration and tax authorities can only roughly estimate the quantity produced which often results in a large discrepancy comparing with real numbers. This leads to difficulties in properly control of national natural resources, as well as series tax loss. Therefore, a system capable of monitoring mine production is much desired so mid and small size coal mines can better manage their production and also solve the potential tax loss issues

Purpose

The main purpose of the system is designed to provide tax authority and administration authority of mid and small size mines a much more accurate data on coal produced, so they can properly understand the production status for a better management and tax control.

Terminology

Weight sensor: a device capable of converting the physical weight to a convenient usable electrical signal

GPRS: a technical approach that uploads the data to the internet using wireless

\section{Main Function}

Real time monitoring and data collection

System power failure and malfunction alarm

System overload alarm

Lifting weight measurement of single-drum and double-drum winches

Real time data storage for one month

Storage content includes: accumulated monthly lifting count and weight

Uploading real time data using GPRS technology 


\section{System Structure}

Working principle and diagram

This digitized remote monitoring system consists of main control board, GPRS module, display, keyboard, and power supply, etc. Its working mechanism is shown in Fig.1, where the weight sensor signal is first converted to a standard 4-20mA electrical signal through a transmitter, then goes through a I/F circuitry, afterwards the generated pulse signal is feed into a pulse counter. Finally the data of the count is uploaded to data center through the GPRS module that is connected to the GPRS internet.

Since this system is mainly used by admiration and tax authorities, it does not provide much value to the mines. So in the field, it excludes display and keyboard. Display and keyboard are designed into a miniature board to facility the input of parameters. Once parameters have been inputted, this small board can be disassembled.
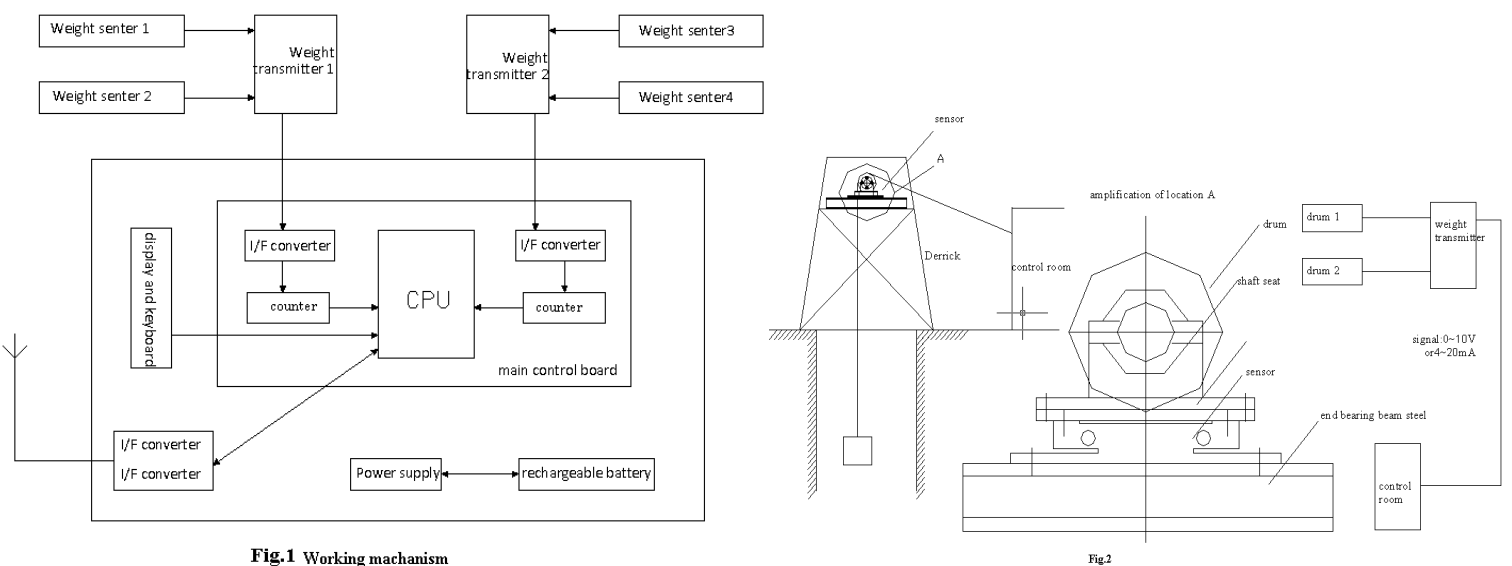

Structure of Collection system (figure 2)

As shown in figure 2, the sensor is designed as a flat double shear structure, where the upper and lower ends are connected to shaft seat and bearing beam using a threaded structure. Considering the issue of lateral force, the connection area is designed to be sufficiently large, also screw selected meets the strength requirement. If consider general requirements, a connection board can be added at the sensor joint with size varied to match the different shaft seats.

The sensor used is made using laser welding seal technique with protection class up to IP67, working environment temperature of $-30^{\circ} \mathrm{C}$ to $70^{\circ} \mathrm{C}$ and long term outdoor operation. The working range of sensors can be selected according to varied installation requirement. Considering the long term stability of operation, it is recommended that real measured weight is about $20 \%-30 \%$ of the maximum capacity of sensors.

Weight transmitter has a standard current output with $20 \mathrm{~V}$ input and 4-20mA output. Varied scale can be chosen for different applications. In this system using $\mathrm{I} / \mathrm{F}$ converter, the current is converted to frequency with range of $10000-50000 \mathrm{~Hz}$. Output of $4 \mathrm{~mA}$ corresponds to a frequency of $10000 \mathrm{~Hz}$, while $20 \mathrm{~mA}$ corresponds to a frequency of $50000 \mathrm{~Hz}$. Output of $>20 \mathrm{~mW}$ will convert to frequency with the same ratio, but it might approach its upper limit. At the end generated pulse signal is counted using a counter and is read by CPU through data line.

There are many I-f circuits available. Since high accuracy is not required, a low cost LM331 is chosen for this application.

LM331 utilizes a new temperature compensation bandgap reference circuit, hence has very good temperature stability, with maximum temperature shift coefficient at $50 \mathrm{p} \mathrm{p} \mathrm{m} /{ }^{\circ} \mathrm{C}$ and compatible 
with any logic form. It can provide single and dual power supply with voltage of $5-40 \mathrm{~V}$, full frequency sale of $1 \mathrm{~Hz}-100 \mathrm{KHz}$, and maximum nonlinear error of $0.01 \%$.

Figure 3 illustrates the basic circuit layout outside LM331

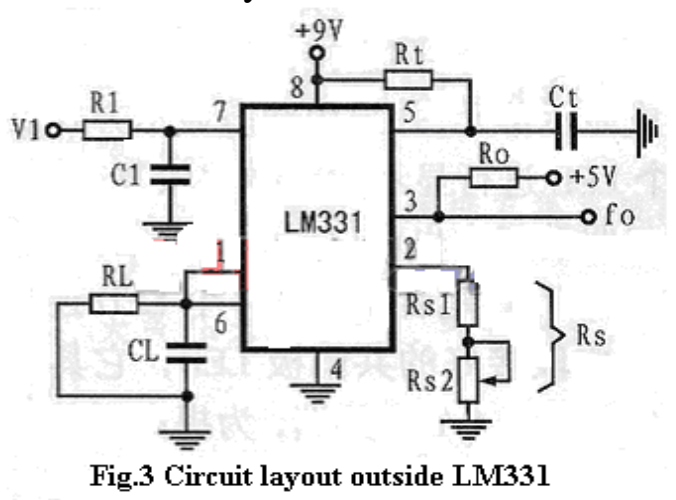

In Figure 3, capacitor $\mathrm{Ct}$ is a charge/discharge capacitor, critical for the circuit stability. A solid stable capacitor shall be chosen in the real application, such as Polyester capacitors etc.

Formula to calculate weight

Weight $=(\mathrm{f} 2-10000) * 1 \mathrm{c} 2 / 40000$;

f2: input frequency

lc2: weight sensor scale

Introduction of power supply design: Power supply design uses a switching power supply design with an input of AC $220 \mathrm{~V}$ and two DC output: V1 is at $13.8 \mathrm{~V}-2 \mathrm{~A}, \mathrm{~V} 2$ is at $13.8 \mathrm{~V}-0.6 \mathrm{~A}$. V2 has a leadacid battery interface, capable of charge and discharge on lead-acid battery. An alternative battery automatically switches in when there is power failure on the main power supply, while when the battery voltage is below $10.5 \mathrm{~V}$, it automatically shut off to protect battery.

The power supplies are set at $20 \mathrm{~V}$ for weight sensor, $5 \mathrm{~V}$ for CPU, $\pm 15 \mathrm{~V}$ for operation amplifier, and $\pm 15 \mathrm{~V}$ for GPRS module. LT1170 is used to boost voltage from $13.8 \mathrm{~V}$ to $+20 \mathrm{~V}$, and then $20 \mathrm{~V}$ is converted into $5 \mathrm{~V}$ and two $+15 \mathrm{~V} .15 \mathrm{~V}$ is split into two lines: one to drive the operation amplifier, the other one to drive GPRS module. $+15 \mathrm{~V}$ used to drive the operation amplifier is then converted into $15 \mathrm{~V}$ to provide negative supply for operation amplifier.

\section{Main Technical specifications}

Power supply: AC220V Wight load: 1T cage, 3T skip

Frequency: $50 \mathrm{~Hz} \quad$ Max load: 24T

Total Power consumption: 20W Weighing accuracy: $1 \%$

Max Range: 20T Environmental Temperature: $-20 \sim+50^{\circ} \mathrm{C}$

\section{Structure Shape}

Features: (1) Easy to hang on the wall

(2) Outside looks like a black box without switch and indicator light. Switches and indicator lights are inside.

(3) Special lock, can only be opened by professionals using speical tools. 


\section{Software design on the mining lift weighing instrument}

This digitized remote monitoring system use a Huabang W77E58 CPU chip as the main processor. Control software is written in $\mathrm{C}$ language. It can communicate with Taxation software through the transmission of GPRS wireless signal. Transmitted data format are: signature +command +parity +data, total 32 bytes. Since the software code is too big, the data processing flowchart is only shown in figure 4

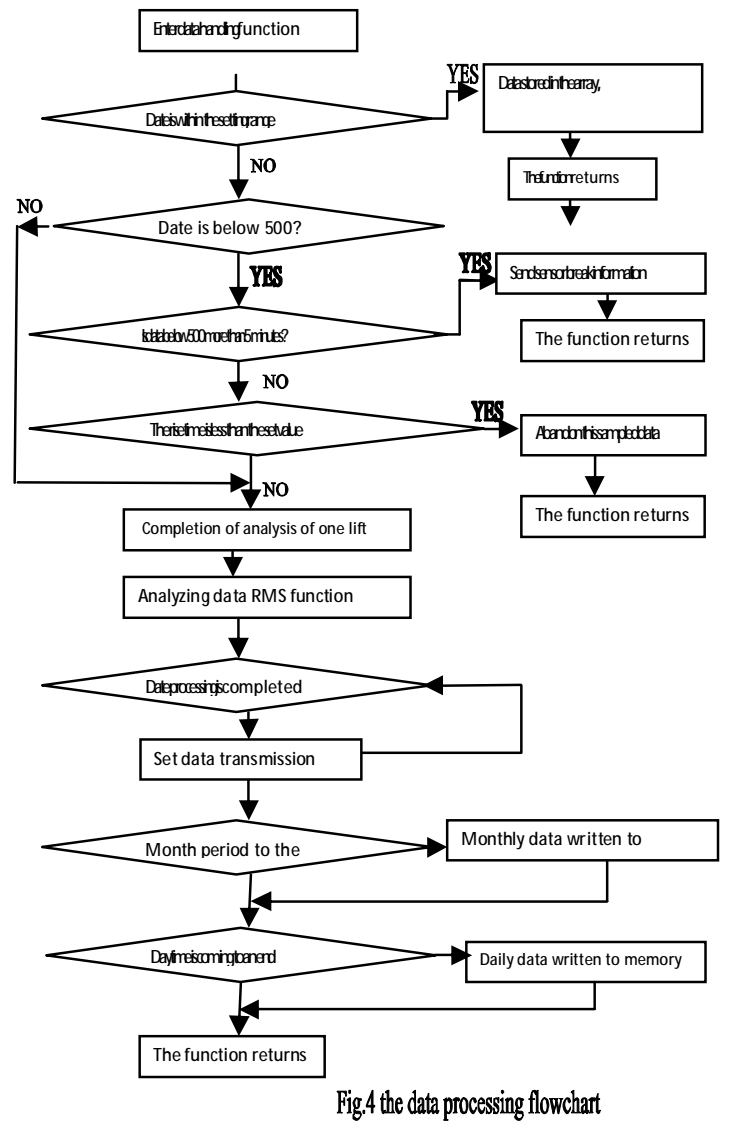

\section{Conclusion}

This digitized remote monitoring system is developed based on the specific circumstances and practical needs of mid to small sized coal mines and non-coal mines. It features small size, light weight, easy to use, especially suitable for mid and small mines to establish throughput control network so correspondent administrative authorities can easily understand the manufacturing status and collect necessary data for a better management and supervision.

\section{References}

[1]: Dai mingzhen, Zhou Jianjiang, The microcomputer interface technology [M], Beijing: Aviation Industry Press, 1993

[2] Song Yucai, Chip microcomputer and its application [M], Jiangsu: Southeast University Press, 1987

[3] Liang Jun etc, Universal GPRS data transmission unit design based on GR64 module, microcontroller and embedded system applications, 2008 